\title{
Influência do formato do aquário na sobrevivência e no desenvolvimento de larvas de matrinxã Brycon cephalus (Osteichthyes, Characidae) ${ }^{1}$
}

\section{Marcelo Mattos Pedreira² ${ }^{2}$ Lúcia Helena Sipaúba Tavares ${ }^{3}$, Robson Campos Silva ${ }^{4}$}

\author{
1 Financiadora: Fapesp. \\ 2 Departamento de Zootecnia - Universidade Federal dos Vales do Jequitinhonha e Mucuri (UFVJM), Rua da Glória 187, Centro, \\ Diamantina - MG. CEP: 39100-000. \\ 3 Centro de Aqüicultura - Universidade Estadual Paulista - CAUNESP, Via de Acesso Paulo Donato Castellane, s/n, Jaboticabal - SP, 14870-000. \\ ${ }^{4}$ Departamento de Ciências Básicas da Saúde - Universidade Federal dos Vales do Jequitinhonha e Mucuri (UFVJM), Rua da Glória 187, \\ Centro, Diamantina - MG. CEP: 39100-000.
}

RESUMO - Neste experimento, utilizaram-se cinco aquários cilíndricos com relevo no fundo (em forma de anel) e cinco retangulares com fundo liso para estudo da influência do formato do aquário na sobrevivência e no desenvolvimento de larvas de matrinxã Brycon cephalus. Observou-se melhor eficiência dos aquários retangulares, confirmada pela maior sobrevivência e biomassa. Os valores de temperatura, $\mathrm{pH}$, condutividade e oxigênio dissolvido foram similares entre os tipos de aquários, sugerindo que esses parâmetros não influenciaram os resultados. O relevo no fundo dos aquários cilíndricos afetou negativamente o cultivo de larvas de matrinxã, pela criação de zonas com pequena capacidade da água em suspender partículas, o que resultou em acúmulo de dejetos, predadores, competidores e alimento. Aquários retangulares com fundo liso são mais adequados ao cultivo de larvas de matrinxã, por promover melhor circulação da água.

Palavras-chave: aquário cilíndrico, aquário retangular, circulação da água, deposição de partículas, larvicultura, relevo no fundo

\section{Effects of two formats of aquariums on survival and development of matrinxã Brycon cephalus larvae (Osteichthyes, Characidae)}

\begin{abstract}
This experiment compared the effects of five cylindrical aquarium with circular relief in the bottom or a rectangular aquariums with flat bottom on the intensive cultivation of matrinxã larvae (Brycon cephalus). Five aquariums of each format were used and the rectangular aquarium was the most efficient, confirmed by better survival average and biomass. Limnological variables were similar between aquariums, assuming that the parameters did not affect the results. The bottom relief in the aquarium resulted in areas with slow flow velocity, which resulted in the accumulation of waste, predators competitors and aliment, showing negative effects to culture of matrinxã. Rectangular aquariums with flat bottom are more recommended for matrinxã culture, because it provides better water circulation.
\end{abstract}

Key Words: cylindrical aquarium, larviculture, particle deposition, rectangular aquarium, relief in the bottom, water circulation

\section{Introdução}

Informações sobre a interação formato do aquário $\times$ dinâmica da água $\times$ comportamento das larvas de peixes são fundamentais para adequação do cultivo, principalmente em sistemas intensivos. Burley \& Klapsis (1985) observaram que, para o fluxo eficiente de água no cultivo de peixe, é necessário determinar a forma correta de abastecimento e drenagem da água no sistema, que depende do formato do tanque e da taxa de suprimento de água. Timmons et al. (1998) observaram que tanques grandes e circulares apresentam uma série de vantagens para produção de peixes, pois podem prover um meio de cultura uniforme, possibilitando operar sob ampla gama de velocidades, otimizando a saúde e a condição do peixe.
A elaboração de um sistema intensivo adequado tem sido largamente discutida (Carvalho-Filho, 1998), pois, apesar da crescente importância do desenvolvimento desses sistemas, os trabalhos envolvendo larvas de Brycon, têm enfocado basicamente o comportamento de canibalismo. Este comportamento tem seu período crítico em torno de 30 a 40 horas após a eclosão (Ceccarelli \& Senhorini, 1996; Ceccarelli \& Volpato, 2001; Dumont-Neto et al., 1997), quando a larva ainda apresenta quantidades razoáveis de vitelo. O canibalismo tem sido considerado a principal dificuldade na larvicultura de Brycon (Ceccarelli \& Volpato, 2001) por comprometer a obtenção de produções comerciais (Gomes et al., 2000). No entanto, Pedreira (2003), utilizando metodologia simples, comparou as formas de sistema intensivo air lift, aeração e recirculação 
na larvicultura da piracanjuba Brycon orbignyanus e encontrou bons resultados.

Considerando-se a carência de estudos em larviculturas intensivas de Brycon e os promissores resultados obtidos por Pedreira (2003), este trabalho foi realizado com o objetivo de avaliar o efeito do uso de aquários retangulares com fundo liso e de aquários cilíndricos com relevo no fundo em forma de anel sobre a sobrevivência e o desenvolvimento de larvas de matrinxã.

\section{Material e Métodos}

O experimento foi realizado no Laboratório de Piscicultura Intensiva do Centro de Aqüicultura da Unesp (Caunesp), em Jaboticabal-SP, no período de 13 a 23 de dezembro de 1998. Larvas irmãs de Brycon cephalus (matrinxã), com aproximadamente 10 horas de vida, $5,9 \pm 0,3 \mathrm{~mm}$ de comprimento total e $1,24 \pm 0,02 \mathrm{mg}$ de peso, foram cultivadas por 11 dias.

Os tratamentos consistiram de dois formatos de aquários (cilíndricos, com relevo no fundo em forma de anel e retangulares com fundo liso) e cinco repetições.

Os aquários apresentavam aeração constante, promovida por um único ponto, e luminosidade, obtida pelo fotoperíodo natural. As larvas foram contadas individualmente e distribuídas em aquários com $10 \mathrm{~L}$ de água, na densidade de 10 larvas/L (100 larvas/aquário). A cada três dias realizou-se a remoção de dejetos, por sifonamento, e a troca de $30 \%$ do volume de água do aquário. A água que abasteceu os aquários foi tratada com ultravioleta e filtrada por elementos porosos de 3 e $5 \mu \mathrm{m}$ e carvão ativado. Diariamente, às $8 \mathrm{~h}$, foram tomadas as medidas de oxigênio dissolvido, $\mathrm{pH}$ e condutividade, a temperatura da água e as temperaturas mínima e máxima do ar.

As larvas foram alimentadas à vontade com plâncton vivo, uma vez ao dia, e alimento inerte comercial (Tabela 1), duas vezes ao dia.

O plâncton foi capturado com rede com malha de $68 \mu \mathrm{m}$ em tanques de piscicultura e, posteriormente, concentrado em um frasco com 4 L, homogeneizado e distribuído na proporção de $400 \mathrm{~mL}$ para cada aquário. Os alimentos foram submetidos à seleção em peneira de $1.000 \mu \mathrm{m}$, com o objetivo, no caso do plâncton, de evitar a interferência no cultivo de predadores e competidores de grande porte. $\mathrm{O}$ plâncton oferecido $(320,0 \pm 116,51$ itens $/ 100 \mathrm{~mL})$ foi composto principalmente por copépodos (Tabela 2).

Ao término do experimento, as larvas foram fixadas e conservadas em solução tamponada de formalina a 10\%, para posterior biometria.
Tabela 1 - Composição do alimento inerte comercial Table 1 - Ingredient composition of the commercial inert

\begin{tabular}{lc}
\hline $\begin{array}{l}\text { Componente } \\
\text { Component }\end{array}$ & $\%$ \\
\hline $\begin{array}{l}\text { Proteína bruta } \\
\text { Crude protein }\end{array}$ & 28,0 \\
$\begin{array}{l}\text { Extrato etéreo } \\
\text { Ether extract }\end{array}$ & 2,5 \\
Fósforo & \\
Phosphorus & 0,6 \\
Fibra & \\
Fiber & 10,0 \\
Minerais & \\
Mineral & 12,0 \\
Cálcio & \\
Calcium & 1,8 \\
\hline
\end{tabular}

Tabela 2 - Composição média do plâncton Table 2 - Average composition of the plankton

\begin{tabular}{|c|c|c|}
\hline $\begin{array}{l}\text { Itens oferecidos } \\
\text { Offered items }\end{array}$ & $\begin{array}{l}\text { Itens/100 } \mathrm{mL} \\
\text { Items } / 100 \mathrm{~mL}\end{array}$ & $\%$ \\
\hline $\begin{array}{l}\text { Rotífero } \\
\text { Rotifer } \\
\text { Copépodo }\end{array}$ & $15,5 \pm 13,42$ & 4,8 \\
\hline Copepod & & \\
\hline $\begin{array}{l}\text { Adulto e copepodito } \\
\text { Adult and copepodit }\end{array}$ & $114,4 \pm 57,26$ & 35,8 \\
\hline $\begin{array}{l}\text { Fêmea ovada } \\
\text { Female with eggs }\end{array}$ & $2,8 \pm 2,16$ & 0,9 \\
\hline $\begin{array}{l}\text { Náuplios } \\
\text { Nauplii }\end{array}$ & $153,7 \pm 51,63$ & 48,0 \\
\hline $\begin{array}{l}\text { Exúvias } \\
\text { Exuvians }\end{array}$ & $23,0 \pm 15,52$ & 7,2 \\
\hline $\begin{array}{l}\text { Cladóceros } \\
\text { Cladoceran }\end{array}$ & $4,2 \pm 3,84$ & 1,3 \\
\hline $\begin{array}{l}\text { Exúvias de crustáceos } \\
\text { Crustacean exuvians }\end{array}$ & $1,4 \pm 2,76$ & 0,4 \\
\hline $\begin{array}{l}\text { Inseto } \\
\text { Insect }\end{array}$ & $0,6 \pm 1,35$ & 0,2 \\
\hline $\begin{array}{l}\text { Organismos não identificados } \\
\text { Unidentified organisms }\end{array}$ & $4,4 \pm 4,45$ & 1,4 \\
\hline
\end{tabular}

As larvas de cada aquário foram contadas uma a uma, para o cálculo da taxa de sobrevivência. Em seguida, determinaram-se a biomassa e o peso médio, utilizando-se uma balança analítica Scientch AS 210 com precisão de $0,1 \mathrm{mg}$, o qual resultou da divisão da biomassa pelo número de larvas sobreviventes. O comprimento total médio das larvas de cada repetição foi obtido medindo-se cada indivíduo com paquímetro.

Os resultados das análises do efeito dos formatos de aquários sobre o desempenho das larvas de matrinxã foram comparados pelo teste t, a 5\% de significância, utilizando-se o programa Sigma Stat 2.0. As variáveis limnológicas foram comparadas a 5\% de significância, segundo teste de MannWhitney Rank Sum. 


\section{Resultados e Discussão}

A sobrevivência e a biomassa nos aquários retangulares foram maiores, enquanto o peso médio e o comprimento total das larvas não apresentaram diferenças (Tabela 3 ).

Os valores médios dos parâmetros limnológicos temperatura da água, $\mathrm{pH}$, condutividade e concentração de oxigênio dissolvido foram semelhantes entre si emantiveram-se na faixa adequada para a espécie(Tabela 4), indicando que essas variáveis limnológicas não foram responsáveis pelas diferenças entre os tipos de aquários.

Durante o experimento, os valores absolutos da temperatura do ar variaram de 21,5 a $33,0^{\circ} \mathrm{C}$, com valor médio e desvio padrão de $27,5 \pm 3,83^{\circ} \mathrm{C}$.

As larvas nas primeiras horas de vida distribuíram-se sobre o fundo, nadando em pulsos, verticalmente. Pouco tempo depois, passaram a nadar horizontalmente, preferencialmente no sentido contrário ao fluxo da água, porém, permanecendo com freqüência no fundo. Entre 25 e 30 horas após a eclosão, iniciou-se o canibalismo, que, segundo Ceccarelli \& Volpato (2001), é acentuado na fase inicial de vida e ocorre até entre larvas de porte similar.

Apesar do canibalismo, a taxa de sobrevivência observada nos aquários retangulares (29,2\%) foi satisfatória, se comparada aos valores observados por Lopes et al. (1994), de 17,0 e $9,0 \%$, em larvas de $B$. cephalus em condições semelhantes às deste experimento. A taxa de sobrevivência registrada nos aquários retangulares coincidiu também com os resultados obtidos por Pedreira (2001), de 7,1 a 18,6\%, e Pedreira (2003), de 22,5 a 22,7\%, em cultivos de larvas de $B$. orbignyanus sob condições similares às deste experimento.

Considerando-se que, em larviculturas de Brycon, Mendonça (1994) verificou taxa de sobrevivência de 5,8\% e Piovezan (1994), de 6,0\%, fornecendo larvas de outras espécies como alimento para minimizar o comportamento de canibalismo, os resultados obtidos neste experimento foram satisfatórios.

Os aquários retangulares mostraram-se mais adequados e proporcionaram maiores valores de sobrevivência e biomassa no cultivo de larvas de matrinxã, diferente dos aquários cilíndricos, que apresentaram zonas de menor circulação de água, acumulando detritos, predadores, competidores e alimentos das larvas.

Backhurst \& Harker (1988), cientes da importância de se manter o alimento em movimento na coluna d'água, deixando-o disponível, demonstraram que tanques quadrados (com aerador tubular ao longo do fundo) e cilíndricos - cônicos (com aerador em um único ponto) são adequados. Neste trabalho, constatou-se a eficiência do aerador em um único ponto em aquário retangular. Os baixos resultados observados com o uso de aquários cilíndricos estão relacionados ao relevo em forma de anel no fundo desses aquários, promovendo uma zona de circulação inadequada para o cultivo de larvas de matrinxã.

Rosenthal (1999) descreveu que as características de mistura d'água no tanque influenciam intensamente o

Tabela 3 - Médias de sobrevivência, peso, biomassa e comprimento total de larvas de Brycon cephalus cultivadas em aquários cilíndricos com relevo no fundo em forma de anel e retangulares com fundo liso

Table 3 - $\quad$ Average ( \pm standard deviation) survival, weight, biomass and total length of Brycon cephalus larvae reared in cylindrical with circular relief in the bottom and rectangular aquariums with flat bottom

\begin{tabular}{lccc}
\hline $\begin{array}{l}\text { Aquário } \\
\text { Aquarium }\end{array}$ & $\begin{array}{c}\text { Sobrevivência (\%) } \\
\text { Survival (\%) }\end{array}$ & $\begin{array}{c}\text { Peso (mg) } \\
\text { Weight (mg) }\end{array}$ & $\begin{array}{c}\text { Biomassa (g) } \\
\text { Biomass (g) }\end{array}$ \\
\hline $\begin{array}{l}\text { Cilíndrico } \\
\begin{array}{l}\text { Cylindrical } \\
\text { Retangular } \\
\text { Rectangular }\end{array}\end{array}$ & $35,10 \pm 6,27 \mathrm{a}$ & $0,46 \pm 0,39 \mathrm{~b}$ \\
Total length (mm) & $15,3 \pm 1,3 \mathrm{a}$ \\
\hline
\end{tabular}

Médias na mesma coluna, seguidas de letras distintas diferem $(P<0,05)$ significativamente, segundo teste $t$. Averages in the same column followed by different letters differ $(P<0.05)$ by t test.

Tabela 4 - Médias ( \pm desvio-padrão) de variáveis limnológicas observadas nos aquários cilíndricos com relevo no fundo em forma de anel e retangulares com fundo liso no cultivo de larvas de Brycon cephalus durante 11 dias

Table 4 - $\quad$ Average ( \pm standard deviation) limnological variables observed in the cylindrical with circular relief in the bottom and rectangular aquariums with flat bottom in the Brycon cephalus larvae rearing during 11 days

\begin{tabular}{|c|c|c|c|c|}
\hline $\begin{array}{l}\text { Aquário } \\
\text { Aquarium }\end{array}$ & $\begin{array}{c}\text { Temperatura da água }\left({ }^{\circ} \mathrm{C}\right) \\
\text { Water temperature }\left({ }^{\circ} \mathrm{C}\right)\end{array}$ & $\begin{array}{l}\mathrm{pH} \\
\mathrm{pH}\end{array}$ & $\begin{array}{c}\text { Condutividade }(\mu \mathrm{S} / \mathrm{cm}) \\
\text { Conductivity }(\mu S / \mathrm{cm})\end{array}$ & $\begin{array}{c}\text { Oxigênio dissolvido }(\mathrm{mg} / \mathrm{L}) \\
\text { Dissolved oxygen }(\mathrm{mg} / \mathrm{L})\end{array}$ \\
\hline $\begin{array}{l}\text { Cilíndrico } \\
\text { Cylindrical }\end{array}$ & $24,5 \pm 1,23 a$ & $7,4 \pm 0,54 a$ & $48,3 \pm 11,6 a$ & $7,6 \pm 0,88 a$ \\
\hline $\begin{array}{l}\text { Retangular } \\
\text { Rectangular }\end{array}$ & $24,4 \pm 1,37 a$ & $7,3 \pm 0,45 a$ & $48,4 \pm 11,3 a$ & $7,7 \pm 0,95 a$ \\
\hline
\end{tabular}

Médias na mesma coluna, seguidas de letras semelhantes não diferem $(P>0,05)$ significativamente, segundo teste Mann-Whitney Rank Sum. Averages in the same column followed by similar letters do not differ $(P>0.05)$ by Mann-Whitney Rank Sum test. 
comportamento dos peixes e que má circulação resulta em altas variações na qualidade da água, tornando as condições de cultivo inadequadas. Ross et al. (1995) observaram que fluxos de água com força e orientação adequadas à espécie resultam em melhor bem-estar fisiológico e maior crescimento, além de diminuir a ocorrência de doenças e o comportamento agonístico entre juvenis de trutas.

O acúmulo de dejetos, de organismos planctônicos, em especial ciclopóides, e de larvas sobre o fundo por um período prolongado, provocou morte ou ferimento das larvas, diminuindo sua capacidade de fuga de predadores e de captura de alimentos. Pedreira \& Sipaúba-Tavares (2002), oferecendo alimento selecionado em peneiras de $1.000 \mu \mathrm{m}$, como neste experimento, observaram que, nos primeiros dias de vida das larvas de piracanjuba $B$. orbignyanus, o acúmulo de dejetos com plâncton sobre o fundo interferiu negativamente na sobrevivência das larvas.

Fregadolli (2003) observou que Thermocyclops decipiens adultos e copepoditos fêmeas no último estádio de desenvolvimento foram capazes de predar larvas de Piaractus mesopotamicus e Colossoma macropomum nos primeiros dias de vida. Além das mortes, o autor relatou que os copépodos promoveram lesões nas nadadeiras, aumentando a susceptibilidade a doenças e a outros predadores, além de reduzir a capacidade de captura do alimento, diminuindo o crescimento das larvas. Esses efeitos negativos tiveram sua magnitude influenciada pela abundância relativa de predadores e cladóceros, de modo que os cladóceros posteriormente serviram de presa para os ciclopóides e para as larvas, amenizando o efeito dos copépodos sobre as larvas.

Basile-Martins et al. (1987) reportaram que adultos de ciclopóides presentes no plâncton, fornecido como alimento, tendiam a se fixar na membrana envoltória ou no corpo das larvas de $P$. mesopotamicus, dificultando a locomoção e, conseqüentemente, levando-as à morte. Behr et al. (1997), estudando o efeito da densidade do Mesocyclops longisetus sobre larvas de pintado Pseudoplatystoma corruscans (5,7 $\mathrm{mm}$ de comprimento total), constataram que os copépodos ciclopóides são predadores extremamente indesejáveis durante a fase inicial de criação. Santos \& Godinho (1994) notaram que o pequeno porte das larvas de pintado (eclode com 3,3 mm de comprimento total, atingindo 5,5 mm com 4 dias) facilita sua predação por ciclopóides.

Fregadolli (2003) sugere que a análise da composição e a abundância do zooplâncton em tanques no início da estocagem ou nos primeiros dias de vida deveria tornar-se uma prática rotineira entre produtores de alevinos no Brasil. Neste trabalho, também foi evidenciada a necessidade da verificação da composição planctônica no início da larvicultura, pois copépodos ciclopóides dos gêneros Mesocyclops e Thermocyclops, são comuns nas bacias hidrográficas brasileiras. Matsumura-Tundisi \& Silva (1999) registraram a presença de $M$. longisetus e o $T$. decipiens na bacia hidrográfica do Rio Grande, onde se encontra o Caunesp e que abrange os estados de Minas Gerais e São Paulo. Esta proposta é reforçada, pois Sipaúba-Tavares et al. (2001) descrevem a ocorrência de $T$. decipiens nos tanques de piscicultura do estado de São Paulo.

\section{Conclusões}

Os aquários retangulares com fundo liso foram mais adequados ao cultivo de larvas de matrinxã.

\section{Agradecimento}

À Sra. Elby Mattos Pedreira e à Fapesp, pelo apoio financeiro; ao criador Martinho Colpani, pela cessão das larvas de matrinxã; à jornalista Léa Cristina Vilela Sá Fortes Pedreira, pela revisão do texto; ao Centro de Aqüicultura da Unesp e ao Dr. Newton Castagnolli, pelo apoio logístico.

\section{Literatura Citada}

BACKHURST, J.R.; HARKER, J.H. The suspencion of feeds in aerated rearing tanks: the effect of tank geometry and aerator design. Aquacultural Engineering, v.7, n.6, p.379-395, 1988.

BASILE-MARTINS, M.A.; YAMANAKA, N.; JACOBSEN, E.O. et al. Observações sobre a alimentação e a sobrevivência de larvas de pacu, Piaractus mesopotamicus (Holmberg, 1887) (= Colossoma mitrei, Berg, 1895). Boletim do Instituto de Pesca, v.14, n.único, p.63-68, 1987.

BEHR, E.R.; FURUYA, W.M.; FURUYA, V.R.B. et al. Efeito da densidade do copépodo ciclopóide Mesocyclops longisetus na predação de larvas de pintado Pseudoplatystoma corruscans. Boletim do Instituto de Pesca, v.24, n. especial, p.261-266, 1997.

BURLEY, R.; KLAPSIS, A. Flow distribution studies in fish rearing tanks. Part 2 - Analysis of hydraulic performance of $1 \mathrm{~m}$ square tanks. Aquacultural Engineering, v.4, n.2, p.113-134, 1985.

CARvalho Filho, J. Editorial. Panorama da Aqüicultura, v.8, n.45, p.3, 1998.

CECCARELLI, P.S.; SENHORINI, J.A. Brycon viabilização da produção de alevinos. Panorama da Aqüicultura, v.6, n.35, p.10$11,1996$.

CECCARELli, P.S.; VOlPATO, G.L. Efeitos da densidade e proporção de presas consorciadas no crescimento e sobrevivência de matrinxã (Brycon cephalus). Boletim Técnico do Cepta, v.14, p.1-18, 2001.

DUMONT-NETO, R.; PELLI, A.; FREITAS, J.L. et al. Reprodução induzida da piracanjuba (Brycon orbignyanus, Valenciennes, 1903), durante a primeira maturação sexual, cultivada em cativeiro, na estação de pesquisa e desenvolvimento ambiental de Volta Grande - CEMIG. Boletim do Instituto de Pesca, v.24, n.especial, p.105-107, 1997.

GOMES, L.C.; BALDISSEROTTO, B.; SENHORINI, J.A. Effect of stocking density on water quality, survival, and growth of larvae 
of the matrinxã, Brycon cephalus Characidae, in ponds. Aquaculture, v. 183, n.1-2, p.73-81, 2000.

FREGADOLLI, C.H. Laboratory analysis of predation by cyclopoid copepods on first-feeding larvae of cultured Brazilian fishes. Aquaculture, v.228, n.1-4, p.123-140, 2003.

LOPES, R.N.M.; SENHORINI, J.A.; SOARES, M.C.F. Crescimento e sobrevivência de larvas de matrixã Brycon cephalus Günter, 1869 (Pisces, Characidae) sob diferentes dietas alimentares. Boletim Técnico do CEPTA, v.7, p.41-48, 1994.

MATSUMURA-TUNDISI, T.; SILVA, W. M. Crustáceos copépodos planctônicos. In: ISMAEL, D.; VALENTI, W.C.; MATSUMURA-TUDISI, T. et al. (Eds.) Biodiversidade do Estado de São Paulo 4: invertebrados de água doce. São Paulo: Fundação de Amparo a Pesquisa do Estado de São Paulo, 1999. p. $93-100$.

MENDONÇA, J.O.J. Criação de espécies do gênero Brycon no CEPTA/IBAMA. In: SEMINÁRIO SOBRE CRIAÇÃO DE ESPÉCIES DO GÊNERO BRYCON, 1., 1994, Pirasununga. Anais... Pirassununga: Centro de Pesquisa e Gestão de Recursos Pesqueiros Continentais, 1994. p.82.

PEDREIRA, M.M. Comparação entre sistemas intensivos de criação para larvas de Colossoma macropomum e Brycon orbignyanus (Teleostei, Characiformes). Jaboticabal, Centro de Aqüicultura da Universidade Estadual Paulista, 2001. 82p. Tese (Doutorado em Aqüicultura) - Centro de Aqüicultura da Universidade Estadual Paulista, 2001.

PEDREIRA, M.M. Comparação entre três sistemas no cultivo de larvas de piracanjuba (Brycon orbignyanus). Revista Ceres, v.50, n.292, p.779-786, 2003.

PEDREIRA, M.M.; SIPAÚBA-TAVARES, L.H. Effect of prey selection and ration addition on the rearing of piracanjuba larvae, Brycon orbignyanus. Boletim do Laboratório de Hidrobiologia, v.14/15, p.99-109, 2002.
PIOVEZAN, U. Efeito da dieta na sobrevivência de larvas de piracanjuba (Brycon orbignyanus) - CAUNESP. In: SEMINÁRIO SOBRE CRIAÇÃO DE ESPÉCIES DO GÊNERO BRYCON, 1., 1994, Pirasununga. Anais... Pirassununga: Centro de Pesquisa e Gestão de Recursos Pesqueiros Continentais, 1994. p.82.

ROSENTHAL, H. The history of recirculation systems: Part 3: Performance of system components. Recirc Today, v.1, n.5, p.23, 1999

ROSS, R.M.; WATTEN, B.J.; KRISE, W. F. et al. Influence of tank design and hydraulic loading on the behavior, growth, and metabolism of rainbow trout (Oncorhynchus mykiss). Aquacultural Engineering, v.14, n.1, p.29-47, 1995.

SANTOS, J.E.; GODINHO, H.P. Morfogênese e comportamentos larvais do surubim (Pseudoplatystoma coruscans Agassiz, 1829) sob condições experimentais. Arquivo Brasileiro de Veterinária e Zootecnia, v.40, p.139-147, 1994.

SIPAÚBA-TAVARES, L.H.; BACHION, M.A.; BRAGA, F.M.S. Effects of food quality on growth and biochemical composition of a calanoid copepod, Argyrodiaptomus furcatus, and its importance as a natural food source for larvae of two tropical fishes. Hydrobiologia, v.453/454, p.393-401, 2001.

TIMMONS, M.B.; SUMMERFELT, S.T.; VINCI, B. Review of circular tank technology and management. Aquacultural Engineering, v.18, n.1, p.51-69, 1998.
Recebido: 04/04/05 Aprovado: 13/09/05 